\title{
URBAN HERITAGE AND CONSERVATION IN THE HISTORIC CENTRE OF BAGHDAD
}

\author{
MAZIN AL-SAFFAR \\ Lecturer, Department of Architectural Engineering, University of Technology, Baghdad, Iraq; PhD Candidate, \\ Manchester School of Architecture, Manchester Metropolitan University, Manchester, UK
}

\begin{abstract}
Baghdad, one of the leading cultural centres in the Middle East, has been a centre of political and economic operations since it was chosen by Caliph Al-Mansur to be his capital city for the Abbasid Empire in $762 \mathrm{CE}$. Up to the 21 st century, the city has been occupied many times by different groups such as the Ottomans (1638-1917), the British (1917-1932) and the Americans (2003), who have all left their marks in varying degrees. The historic quarter of Old Rusafa is one of the areas of the city where historic buildings going back to the early 13 th century have resisted the power of transformation, such as Al Mustansiryia School, The Abbasid Palace and Al Khulafa Mosque. This article will address how the traditional compact urban fabric in Old Rusafa has witnessed irreparable damage because of wars, a weak definition of demands and an ambiguous formulation of what to preserve. These are some of the reasons that the majority of urban conservation plans prepared by different groups for the city centre have not been successful. The article will address revitalizing urban heritage in Old Rusafa as an example of preserving the urban system and its components in historic cities. It will also argue the significance of preserving these historic places and how to promote socioeconomic and sustainability aspects. Finally, preserving traditional areas will require implementing efficient and sustainable urban development strategies that drive urban evolution and encourage revitalization of the historic centre.

Keywords: conservation, sustainability, urban conservation, urban fabric, urban pattern.
\end{abstract}

\section{INTRODUCTION}

Everard and Pickard [1] mention that conserving the built heritage can protect and promote identity, the significance of place, cultural value, aesthetic value, as well as an economic and commercial value. They suggest, "The "psychological and aesthetic value" of the conserved environment is so important that knowledge of peoples' conscious or subconscious commitment to buildings from the past should play a crucial part in the development of conservation policy and practice'. They also write, 'There may be "multi-faceted outcomes of conserving the cultural built heritage in terms of the dynamic benefits to society", and conclude that "the cultural heritage is an economic, tourist, scientific, educational and sustainable asset which needs to be protected by the commitment of the whole community through partnership of public and private sectors"' [1].

Since policymakers and urban authorities have turned to 'culture' as an instrument for urban regeneration, the importance of historic environments has become increasingly evident as part of urban regeneration initiatives [2]. At the same time, 'Conservation initiatives try to enhance strategies which not only ensure the continuing contribution of heritage to the present and the future through the thoughtful and intelligent management of change responsive to the historic environment and collective needs, but also the preservation of fundamental elements of social environments. Such strategies will lead to more equitable and sustainable solutions to the problems currently faced by the historic quarters' [3]. 


\section{CONSERVATION IN THE URBAN CONTEXT}

The past century has been one of unprecedented change in terms of impact on the urban environment. The issue of conservation of historic urban areas was seen in a new light in the late 1980s, partly due to the growing concern for the environment and situations of poverty in many countries, as well as disasters and armed conflicts [4]. The main factors driving change in the urban environment are globalization, rapid uncontrolled development, demographic changes and economic pressures, which directly influence the preservation of historic urban environments. Many challenges emerge in the conservation of built heritage but the main one is the original uses are to be changed while preserving the importance of the area and its buildings [5].

The population growth in cities, as Al-Saffar [6] debates, will rise to more than $60 \%$ of the world population by 2050 , and this increment will lead to increase the pressure in various urban places. He argues that built heritage resources and traditional places are under threat in responding to modern business forces. He asserts that urban conservation can offer new sustainable methods to deal with socio-economic and environmental problems. He adds that urban conservation can develop the historic physical environment, offer new jobs opportunities and improve the quality of life in run-down areas. He states, 'Conservation policies can play a significant role in promoting, managing and protecting our built heritage in terms of its socio-economic and environmental aspects' [6].

Conservation is discussed by Ebrahimi in the following terms (2015): 'In preserving and maintaining the frame and concrete architectural structure; however, the growth of awareness alongside attention to other aspects caused different aspects to be effective in recognizing and evaluating the values' [7]. In addition, it 'is the action was taken to prevent decay and manage change dynamically. It embraces all acts that prolong the life of our cultural and natural heritage' [8]. Conservation policies and measures have changed due to the alteration in the principles of urban conservation. Peerapun [9] has stated according to International Council on Monuments and Sites (ICOMOS) that coherent strategies of socio-economics development and of urban planning at every scale should be a complementary aspect of the conservation of historic urban areas. He has added that one of the essential elements for the success of conservation programmes is public participation [9]. Conservation aims to be a part of broad procedures of promoting the existing physical-built environment and affects all citizens in a community. Glendinning [10] argues that architectural conservation is something that embraces different forms and subjects such as urban design, housing, environmental issues and renewal [10:1].

\section{URBAN CONSERVATION}

During the 19th century, the infrastructure of land uses, buildings and streets suffered from different issues typically linked with urbanization, for instance, poverty, migration, overpopulation, unemployment and segregation. Improving the quality of urban areas in recent years has become a response to the challenges displayed by citizen's mobility, which require the physical renewal of declining inner urban spaces in a flexible way. Cities show endless examples of neglect that manifests high rates of decline in their urban fabric. These areas are widely connected with historical layers of urban change during which they have, over time, advanced, declined and sometimes been renovated. The narrow alleys found in Cairo, London, Rome and Athens are representing vibrant models of this. Various actions to conserve these fortunes were framed in combinations of policies that have seen positive results in the recent years [11:14-15].

Urban conservation, as Cohen [12] points out, is a cultural necessity 'due to the increasing tendency of city dwellers to move back into historic centers, urban conservation is becoming an ever more urgent issue' [12:9]. Albrecht [13] has stated that 'urban conservation' was 
used by others more broadly to include environmental factors as well as socio-physical and socio-cultural issues. Moreover, he defined urban conservation as 'protecting and managing the valuable ecological spaces and species in and around cities, as well as the ecosystem services that they provide' [13]. Pendlebury and Strange [14] debate that the power in shaping the planning of the contemporary city is the practice of conservation of the historic environment [14]. $\mathrm{Su}$ [15] has stated that over the last three decades urban conservation has become a substantial element to promote urban competitiveness in the global economy, asserting that one of the main purposes of urban conservation is to promote the historical physical environment and ensure its continuity as an attractive place to live [15]. Al-Saffar [6] mentions, 'Since policymakers and urban authorities have turned to "culture" as an instrument for urban regeneration, the importance of historic environments has become increasingly evident as part of urban regeneration initiatives' [6]. Puren and Jordaan [16] suggest, 'A shift in how urban conservation is viewed in the sense that it should move from preserving heritage resources as isolated objects towards a more integrated view where heritage resources are proactively integrated into the contemporary uses and future development of cities to ensure the continued existence of these assets' [16]. Therefore, urban conservation, as Koramaz and Gulersoy [17], mention, will require comprehensive spatial analyses and investigations devoted to the evaluation of urban historic areas [17].

\subsection{Urban conservation and society}

In recent years, governments, practitioners, experts, academics and international organizations have considered urban heritage as urban areas rather than single monuments. They moved towards utilizing citizen participation in order to preserve, manage and control urban conservation plans. The bottom-up approach has become an essential factor in cultural heritage issues creating new opportunities for citizens' participation in the decision-making process of urban conservation. Sarvarzadeh and Abidin [18] point out that citizen participation has the ability to improve the practice of urban conservation and assist policymakers in identifying opportunities and challenges [18]. Stakeholders were expected to have various knowledge and experience, and interest in, cultural heritage resources. However, governments and professionals considered citizen's participation in forming and responding to the social needs of societies [19]. Al-Saffar [6] mentions, 'There is an interaction between what people build and what they believe, mentioning that people structure their environment and are influenced by it in their attitudes as a result of interaction with it over time' [6].

In Old Rusafa nowadays, enhancing the concept of identity and developing the traditional social values are a new tendency. The historic centre is represented by the important role of culture, religion and the most significant element social structure. The physical and social situations are depressed in this traditional area; however, it is still the source of cultural inspiration for citizens, and people still prefer to go back and live in the traditional neighbourhoods where they grew up. This area has community representatives who could participate and promote conservation processes more than the official administrative body in such areas [20]. One of the significant elements to advance the urban conservation plan is to create a cooperation between the city's stakeholders and urban designing experts. Pieri [21] argues, 'In the case of Baghdad, a city in which there were so many urban and architectural additions throughout the twentieth century, preserving a "continuity" does not only imply the formal level, but also the practical appropriation of the urban space. Baghdad's renaissance should not depend on arbitrary external criteria deciding what is beautiful or ugly, good or bad, but on a cautious analysis of the physical needs and the mental representations of its inhabitants, balancing between objective, subjective and even symbolic data' [21]. 


\subsection{Urban conservation and economic}

Yung and Chan [5] have argued, 'Conservation of historic buildings and places contributes to a higher degree of creativity and economic development as well as a better quality of life and the social well-being of different groups. However, a key issue in heritage conservation is the use of the heritage and its vital interface with both culture and identity' [5].

Economics is the most important element that might enhance and encourage governments to plan a new strategy for developing the traditional cores in historic cities. The majority of historic centres in Iraq are concentrations of local industries that are the main source of traditional and cultural goods and services, not only for local residents but also for visitors and the whole population in the country. Urban conservation of historic areas has the ability to motivate these traditional industries, generating incomes and employment for local citizens and businesses. This will lead to increasing the rate of internal and external tourism that might be one of the fundamental elements of significant revenue; tourists are usually attracted by the traditional areas that represent cultural identity. This will form a new and essential commercial area for the traditional products of the city. If these historic centres are ignored or demolished, the city will lose these advantages [22].

Old Rusafa has strong economic bases and contains many significant commercial markets such as Shorja Suq which has a national role. This area is considered as the main commercial centre of Baghdad and showed the characteristic division of trade, goods and crafts (Fig. 1).

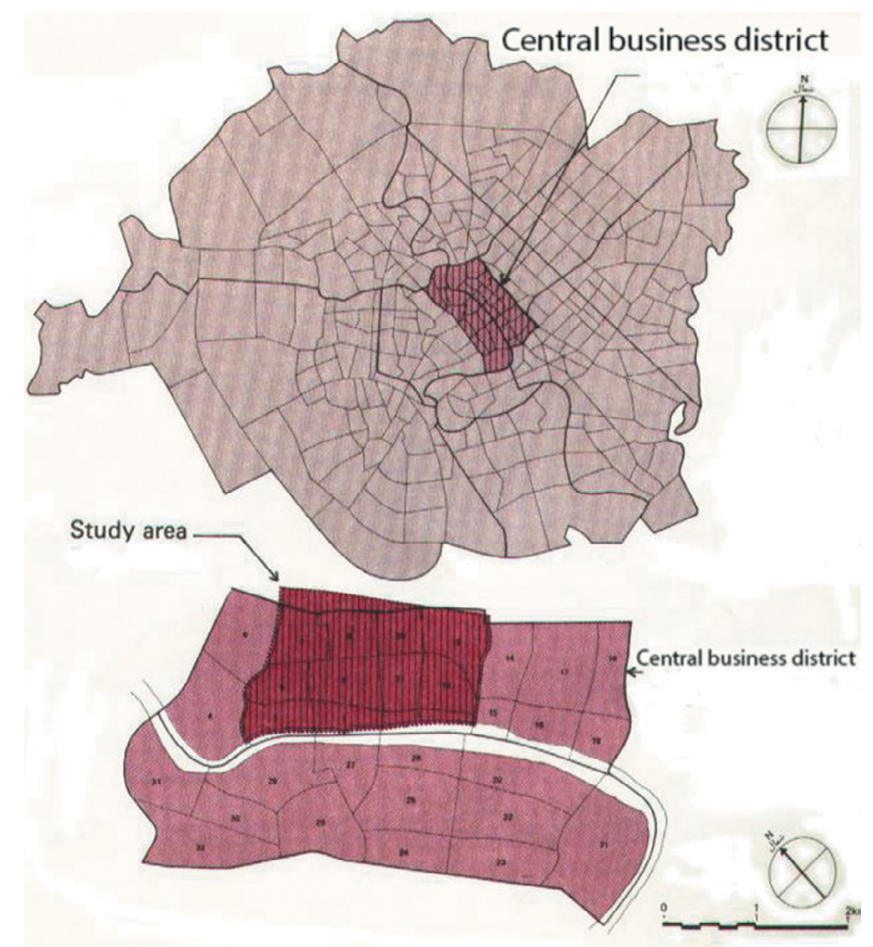

Figure 1: Old Rusafa as part of the Central Business District in Baghdad (CBD). Source: [28]. 
These markets or suqs are located in a particular place that is usually connected with its adjacent specialized suq. Sarai Suq, for example, is close to Mutanabi Street, the first one specializes in books and stationery, and the second specializes in print works, libraries and book storage. A second example is Sarafin Suq, which is occupied by moneylenders and exchange, but is just located near a modern street of banks. Furniture, car repair, metalworking and textiles are the significant industries in Old Rusafa. Various challenges and problems have faced the national economy such as ongoing conflict, no access to adequate private investment and lack of official promotion of popular interest in urban conservation. In addition, the land around the commercial centre has witnessed an increase in its price, and the nature of materials and high standards of craftsmanship that are needed to preserve this area are very expensive [20].

\subsection{Urban conservation and sustainability}

In the last few years, we have seen plenty of research on the urban conservation of traditional areas. The consequences of these literatures have endeavoured to find a connection between urban conservation and the ability of cities to transform to a sustainable future. Shwartz et al. [23] clarify that 'researchers, advocates, and policymakers have proposed urban conservation as an emerging, integrative discipline that can contribute to sustainable cities by delivering co-benefits to human and non-human components of biodiversity' [23]. Hiu and Hon (2012) state that 'built heritage is extremely difficult to survive in a city if they are not conserved in a sustainable way'. Preserving traditional fabric and enhancing the character of a place are not the main concern of urban conservation nowadays, but how would urban conservation be sustainable. To move to this stage it demands the involvement of the environmental, social and economic issues in urban conservation in order to promote the quality of life for all citizens and to create a better place to live and work. Social equity, inclusiveness and action are consistent with the concerns of built heritage conservation as part of sustainable development [5]. Sustainable city planning is an essential issue in historic cities that seek to create liveable places for public, green areas and perfect physical environment that is required for a better society life [24]. Heritage and sustainability in the 21 st century share the widest common base when both are preserved first as being ongoing processes rather than immediate end products, and second as being people-centred (culturally as well as socially) rather than object-oriented [25:20].

Cities nowadays, as Al-Saffar [6] debates, are facing many fundamental challenges in terms of developing sustainable urbanism. He indicates, 'One of these challenges is how to solve problems of unsustainable geographical expansion patterns and ineffective urban designing and planning methods that have increased the number of slums areas, unsuitable delivery of basic services and inefficient resource use, and poverty'. He confirms, 'Previous studies have not illustrated a clear vision for dealing with the assets of urban heritage and their relationship with environmental, social, and economic issues, especially in an age of such significant transformation. Therefore, an evaluation of urban heritage conservation under the light of sustainable urban design is required to regenerate urban form and fabric'. In terms of Old Rusafa, he says that the organic traditional urban fabric was the first stage for sustainable thinking. He asserts, 'The compact area of narrow alleys and traditional Baghdadi houses are oriented in a defensive posture against the wind-borne dust, and the direction of the sun must be determined for all hours of the day at all seasons along with the direction of the prevailing winds, especially during the hot season'. He states, 'The features of the old urban fabric 
represent the main principles of environmental sustainability and shows how individuals in the past built a sustainable environment to face the tough climate' [6].

\section{URBAN HERITAGE CONSERVATION IN HISTORIC CITIES}

In the last five decades, various projects, research and proposals have been produced to preserve historic cities in the world and especially in the Arab world. Cultural heritage has contributed to promoting the economic, social and cultural life of cities in the developing countries. We can find the heritage in the historic core of alleys and traditional buildings that have resisted the power of modernism. The significance of preserving these iconic historic buildings and areas is to obtain economic, social and cultural goals. Hence, policymakers, architects and urban designers require the creation of a new approach that connects the architectural and cultural functions of heritage in the urban spaces. In several historic cities in developing countries, the long-term methods of urban evolution have bypassed quarters where alleys, patterns, urban fabric, social and heritage activities have been kept unchanged for many centuries [22].

Historic cities have transformed into paths of cultural activity by using appropriate urban conservation, which is not only preserving some significant building but is a compressive approach to protecting and conserving the whole historic urban structure [12:9, 11]. Bianca [26] argued that the Industrial Age has affected the dynamics of the socio-economic issues and has helped them to find their physical term in the substantial transformation of historic cities, while changes in the architectural fabric through former centuries had usually happened as part of a natural evolutionary process [26:174]. Shin [27] observes that due to local entrepreneurialism, cities have employed different strategies in order to compete for increasingly footloose capital and citizens. Conservation of historic areas has played a fundamental role in promoting economic development in cities. Consequently, urban historic centres, and plenty of significant monument and architectural heritage, have gained renewed interests in the last few decades for their socio-economic value [27].

\section{URBAN CONSERVATION IN HISTORIC CENTER OF BAGHDAD (OLD RUSAFA)}

Old Rusafa is the historic centre of Baghdad and has a long history going back to thousand years. This old core has become a complex urban organism as Al-Saffar [6] says. He shows, 'The area of Old Rusafa once enclosed within the old wall is approximately 5.4 square kilometers, has a population of about 203,000 (1980), and contains nearly 15,700 buildings. Currently, Rusafa forms a contracting mixture of dense irregular traditional fabric and gridiron modern developments often conflicting with each other in form, scale, and function'. He asserts, 'The importance of Old Rusafa is of not only local but also regional and national dimensions. It contains the biggest concentrations of traditional suqs and workshops and some of the most significant mosques and government and administrative buildings in Iraq'. He also adds, 'Old Rusafa contains several significant historic buildings: 132 monuments are listed, twenty-one monuments of which belong to the Abbasid Empire (762-1258) and the rest to Ottoman Period (1638-1917). Therefore, it is considered as an important heritage that demands emergency protection for its historic identity'. He illustrates that the historic core has suffered from many problems such as destruction of many buildings and deterioration of the traditional urban fabric [6].

One of the significant comprehensive urban conservation master plans for Old Rusafa was submitted by Japan planners, Architects and consulting engineering (JCP) in 1984. Urban conservation and redevelopment of the traditional core were the main aims of this scheme. This project proposed a buffer zone around the old centre by promoting the advancement of a Central Business District. This master plan was only partly implemented due to the political 
condition from 1990 until now. The proposed conservation scheme designates conservation places and monuments to ensure their protection. It also offers solutions that minimize the damage as much as possible be the removal of eyesores, development control, incentives for restoration and by environmental rehabilitation and revitalization. JCP plan [28] designates conservation places within Old Rusafa, identifies building by building, their typology and architectural interests, and suggests diverse criteria for intervention, restoration, urban repair, infill or substitution. A methodological approach for such intervention and a corresponding 'manual' for the use of The Municipality of Baghdad are proposed in order to permit it to control ongoing growth. They assert that conservation and development in the historic core should be implemented in the progressive stage and can succeed only when other equally necessary legal, administrative and financial tools are provided. The importance of this plan is not envisaged as merely a passive protection of the existing historic centre. In addition to proposing the conservation, restoration or rehabilitation of significant portions of the historic centre, the structure plan and urban design schemes aim for an active development of the historic fabric. This includes the retrieval of many fundamental parts which, if realized, would greatly improve the image of Old Rusafa (Fig. 2) [28].

In recent years, to conserve the historic part of Baghdad, many initiatives and projects have been prepared by The Municipality of Baghdad to protect the historical physical environment of Old Rusafa and display the socio-economic and environmental problems. However, these plans have concentrated on demolishing big parts of the traditional urban spaces or on simulating the Western countries' methods of urban growth. Furthermore, these initiatives did not consider citizens' participation as a main element in making decisions (Fig. 3) [20].

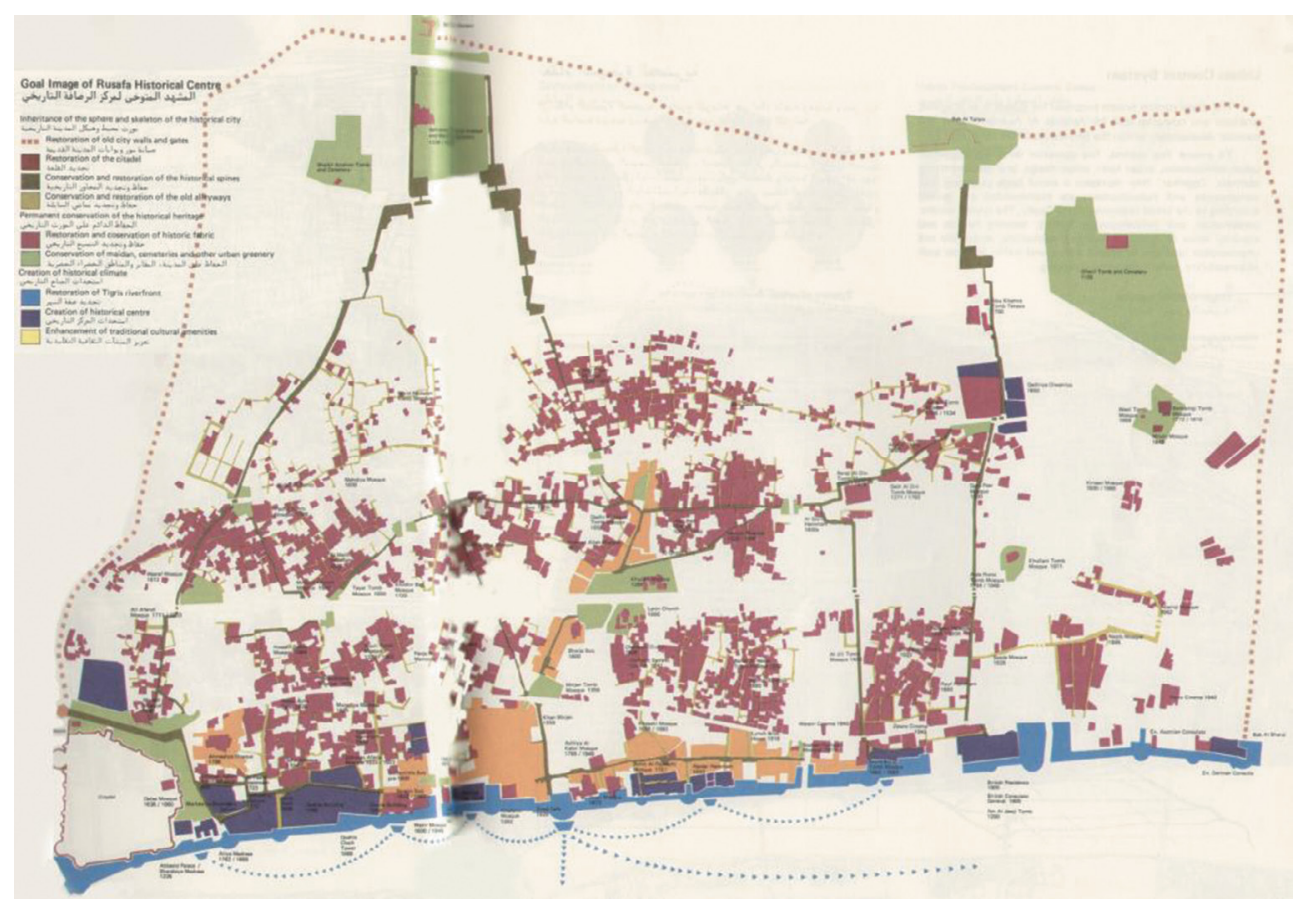

Figure 2: Goal image of Rusafa historic centre. Source: [28]. 


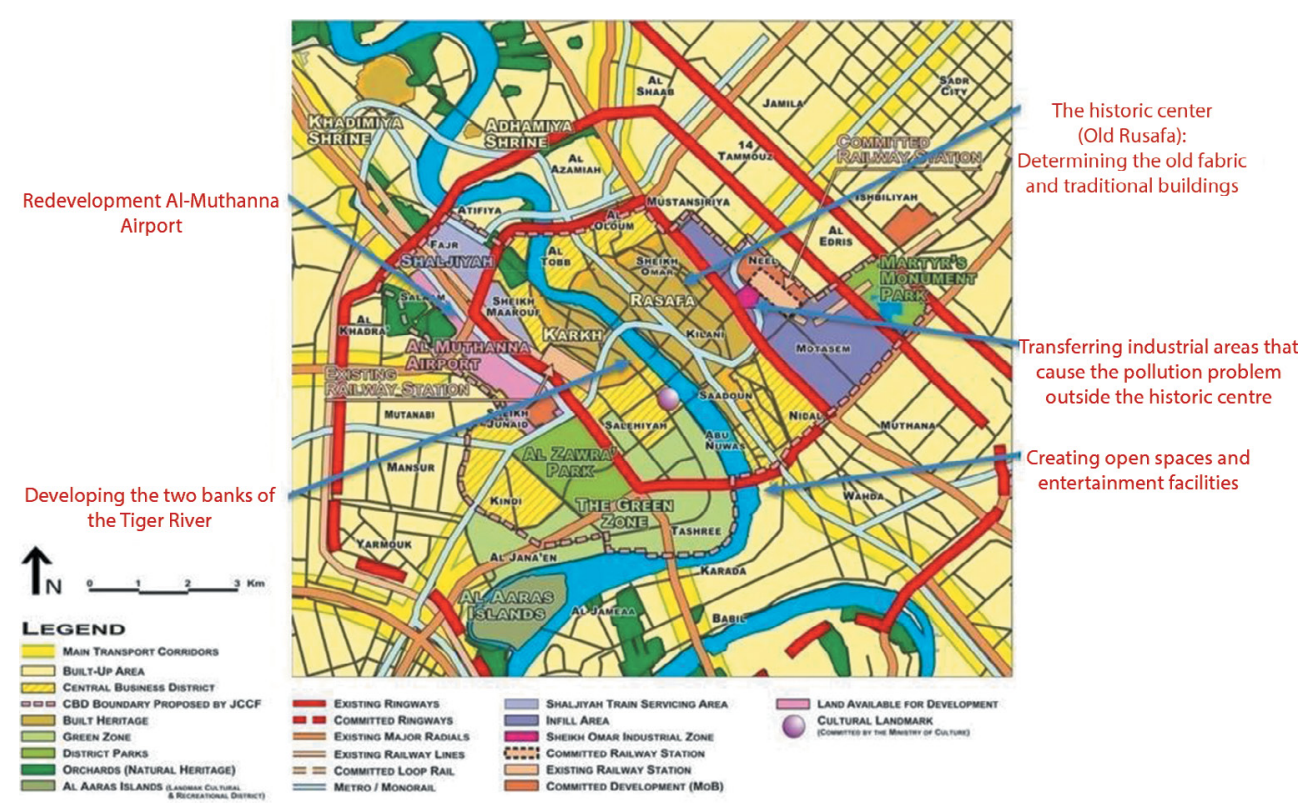

Figure 3: Short-term development strategy for the central business. Source: Author [6] according to The Municipality of Baghdad.

\section{REVITALIZING URBAN HERITAGE IN OLD RUSAFA IN TERMS OF ITS URBAN PATTERN AND URBAN FABRIC}

The beginning of the modernization in Old Rusafa started in 1869 when the Ottoman demolished the old city walls that were built during the Seljuk rule (1052-1152 AD) and constructed the first residential extensions. The layout of the old city did not change much between the Seljuk period and the end of the 19th century. Many problems have led to the deterioration of the structures of the historic centre that were constructed of brick and timber and had to be rebuilt periodically due to frequent flood damage and fire. One of the main problems was the opening of four major roads between 1914 and 1956 which linked the northern and southern limits that had led to the dissection of the continuous urban fabric into isolated fragments (Fig. 4). The second problem was the rehabilitation of the disrupted urban form on both sides of these new roads that were given over to wholesale redevelopment, huge areas of old urban fabric been demolished and the rest of the traditional urban fabric was ignored. The method of transforming the city centre from the traditional to the modern was another problem, which has been affected not only physically, but also socially, by the departure of the original people of Old Rusafa into new modern areas. A new community from rural areas in search of employment and a better life filled the social vacuum in the old city by renting the traditional houses, usually one family per room. Furthermore, property owners were not interested anymore in preserving their properties. These circumstances have led to acceleration of the physical deterioration.

Four main types of urban form were identified in Old Rusafa by JCP planers. The first type was the traditional homogeneous places located mostly between Khulafa Street and Kifah Street. The second type was the traditional fabrics built between the two World Wars, including Rashid and Kifah Street. Modern fabric blocks was the third type starting in banks District Khulafa street in 1950s, and finally, the Shikh Omar area developed in the early 1940s consisting mostly of large, one-storey garages, stores and services workshops. JCP planers tried to achieve compatibility between these different urban forms in Old Rusafa; conservation 


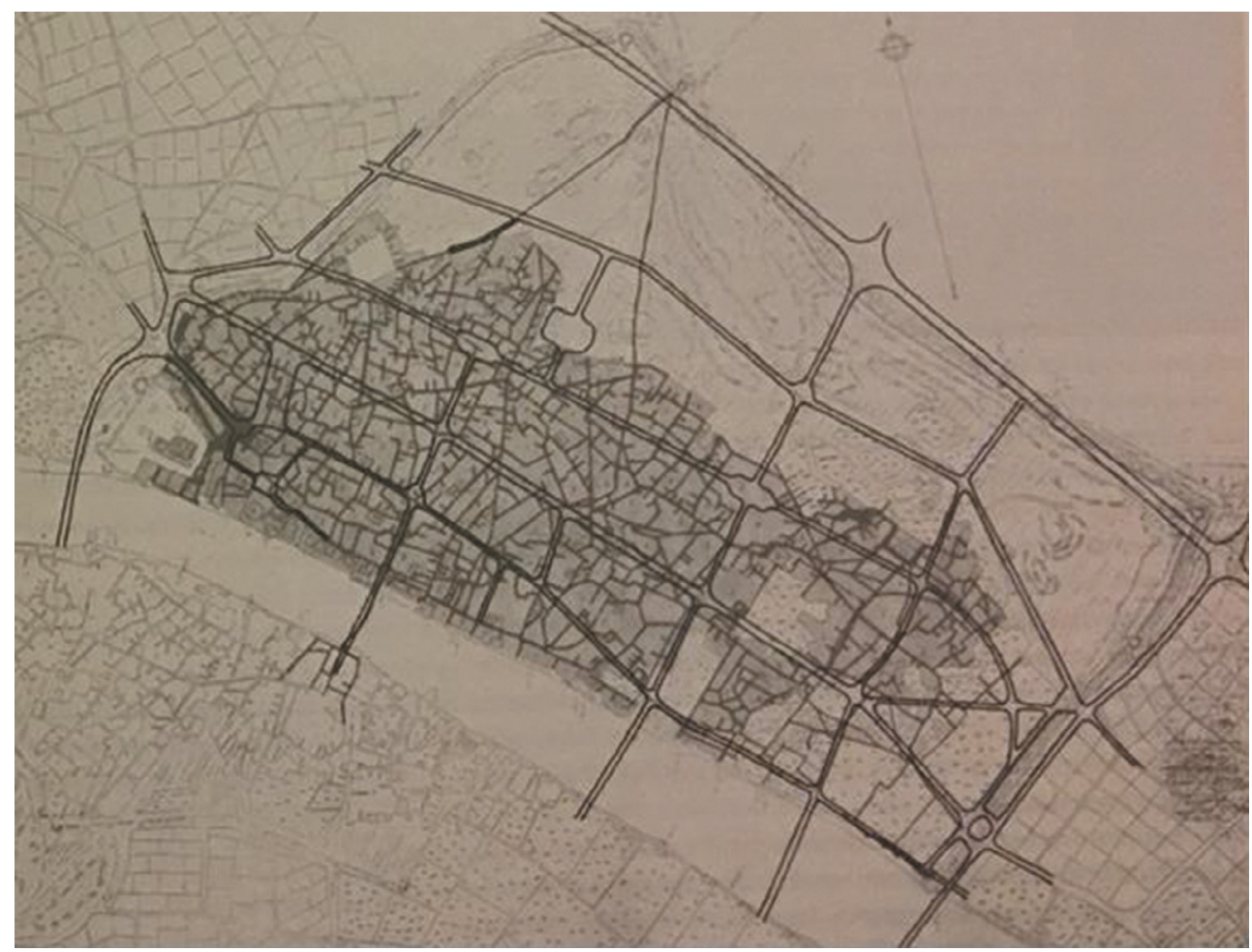

Figure 4: Old Rusafa from 1854, overlapped with the new urban system. Source: [26:251].

and urban design plans are approached as complementing each other. Therefore, to attain this aim they suggest that The Municipality of Baghdad should apply development control in two stages: First, by passive control with guidelines and regulations to control private growth in conformity with plans. Secondly, through active control by assisting or initiating comprehensive development projects to assist the implementation of the overall concept. Several focal places in the historic centre were selected by JCP planers to illustrate these approaches such as the riverfront, Rashid Street, historical spines suq system and Sheikh Omar zone [28].

Bianca [26] argued that the traditional urban fabric in Baghdad required a new scheme to solve the broken structure of the urban system, before producing a comprehensive plan for the historic centre that might propose a total redevelopment including the conservation of a few isolated historic buildings. He also suggested relinking the current components of the urban system in order to integrate the remains of the traditional urban fabric and precious urban characteristics [26:250-256]. Therefore, to create an efficient urban conservation in Old Rusafa, we should consider and improve all socio-economic issues and produce a holistic approach to revitalizing urban components of the urban system in the city centre of Baghdad.

\subsection{Urban pattern}

Population growth is the main reason for current urban development in various urban areas worldwide. This has shown a great concern about a reduced quality of urban patterns and the quality of life of the urban resident. In other words, the lack in quality of urban patterns will result in a reduction in the quality of life of the urban resident. Hence, huge efforts are made 
to evolve new procedures for improving the socio-economic and environmental condition that might transform current urban patterns towards a higher quality. Wissen Hayek et al. [29] say, 'Urban areas are highly interlinked systems with human agencies and urban patterns, both affecting socio-economic and ecological processes at various spatial scales' [29].

Cohen [12] point out that the concept of the best urban pattern should have the basis for sustainable life and has the ability to encourage the present towards self-preservation without ignoring the new one. He asserted that this concept would require implementing a few general conditions. Firstly, one must consider the idea of the whole in relation to the size and the character of the city. This method will clarify the structure and allow us to make decisions more quickly and control the non-essential mistakes. In this case, the new pattern will have the ability to accommodate itself in a well-identified framework with the past. Secondly, one should determine the fundamental elements that constitute urban patterns including building style and spaces that define human actions in such an area. Lastly, the main components in the urban fabric should have the capability to affect local elements in order to improve relationships and overcome what is usually detrimental [12:19].

In the past decades, Baghdad city has experienced extremely great changes in its urban patterns. Many new buildings and modern road facilities were built in the historic city centre. The new type of urban area and modernism movements has affected the identity of the existing traditional urban fabric, which has led to the creation new urban pattern within the old one (Fig. 5). Al-Hasani [30] argued that the conflict between various patterns could be solved by defining the area between them and developing it in a better way to use it between diverse users and functions. He also debated, 'The self-organized urban form was interrupted by a planned and planted one. The result was two different space languages competing against each other. Those new added urban elements have created an interrupted urban pattern, which

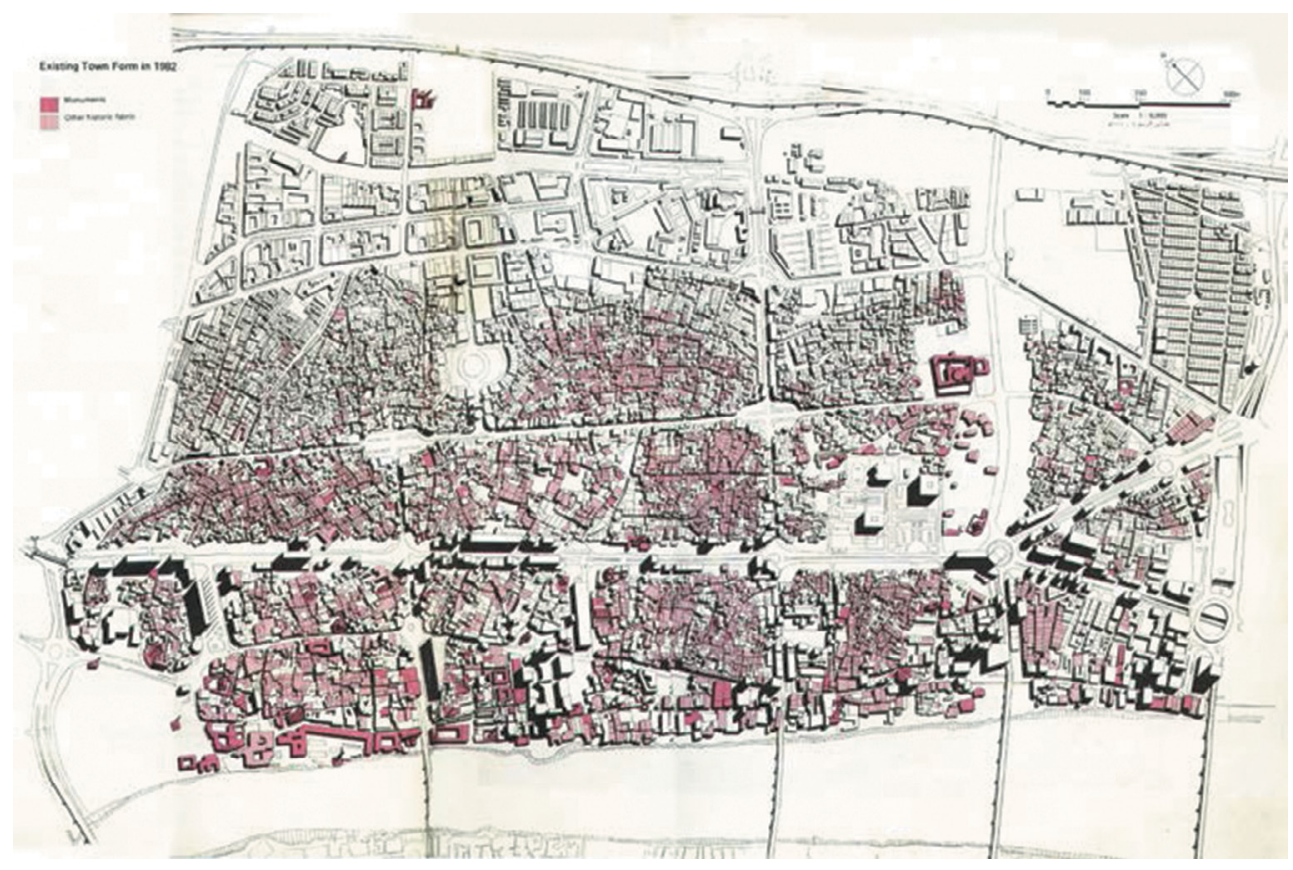

Figure 5: The new urban pattern within the old fabric (Old Rusafa). Source: [28]. 
was so far from having continuity, coherence, and integrity with the surroundings. The quality, use and nature of the urban space in Baghdad is based on different spatial concepts, urban patterns and building typologies' [30]. However, the historic urban area in a city centre has a high mixed land use pattern and still contains many essential features from the past; further, it not only represents the concentrated residential area but also the commercial, political and cultural centre of Baghdad city.

\subsection{Urban fabric}

Old Rusafa is the historic centre of Baghdad city, and due to that, its fabric has been under pressure from modern development and has suffered tremendous losses in its traditional form. However, there is still an opportunity to preserve the rest of the unique fabric by promoting these areas with new facilities and fixing the broken structure. The historic centre has witnessed some conservation by the Municipality of Baghdad in its fundamental buildings and street such as the Al-Mustansyria school, the Baghdadi Museum, Khan Merjan, Al-Rashid Street, the historic castle which is used as the Ministry of Defense, and many tombs, mosques, houses, cafes and squares (Fig. 6) [20]. Al-Saffar [6] debates, 'There are many elements that emphasize the unique urban fabric that makes the Old Rusafa so special such as traditional suqs, Rashid Street, khans, churches, and significant mosques. Conserving these archaeological and cultural features will promote heritage values in Baghdad'. He emphasizes, 'Rescuing the Old Rusafa by regenerating its urban fabric, the five historical spines, and Baghdadi courtyard houses will enhance the quality of life and achieve equity'. He clarifies, 'Traditional urban fabric needs a green and new urban infrastructure that helps to reach environmental and health standards' [6].

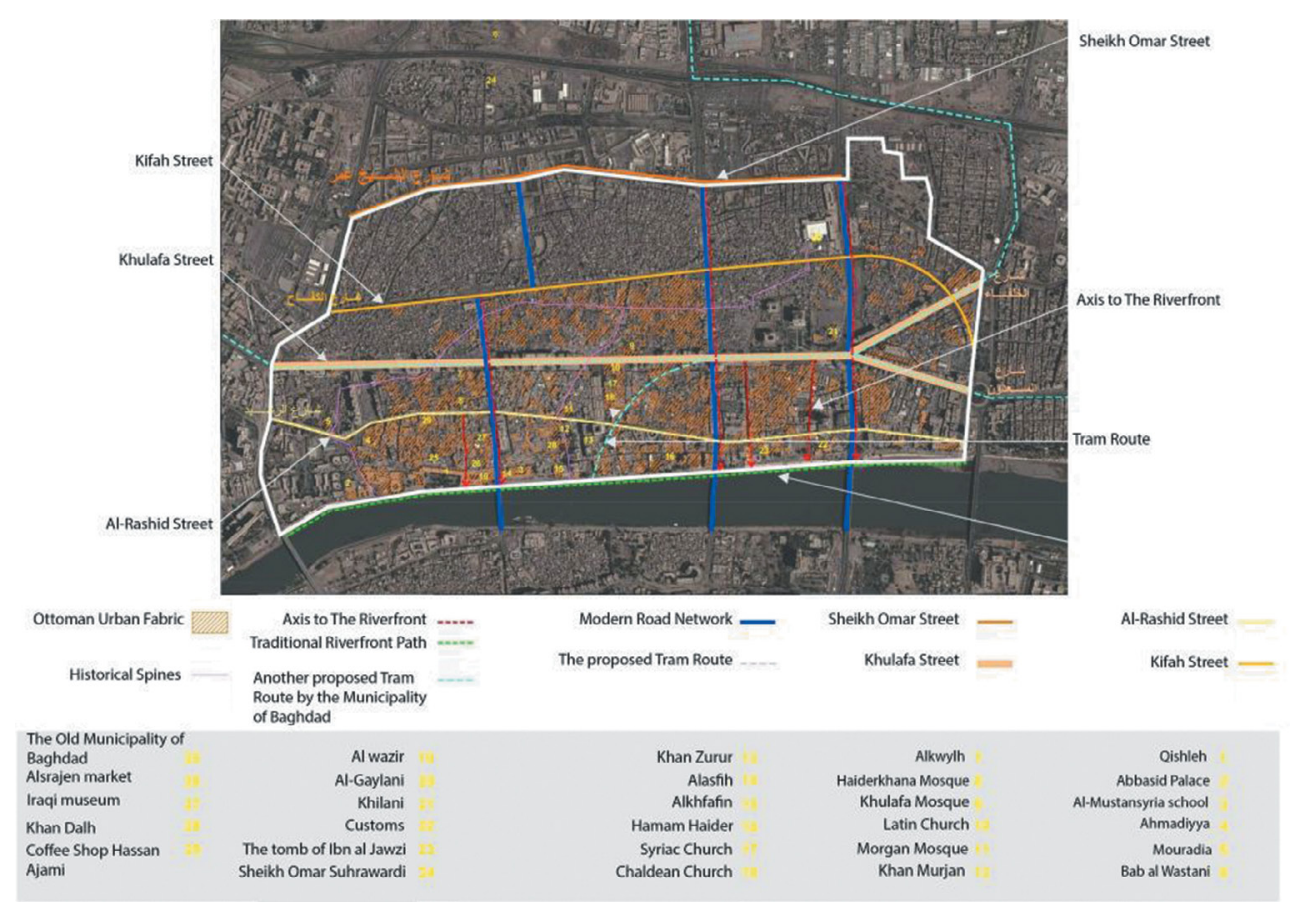

Figure 6: Urban conservation strategy in old Rusafa. Source: Author [6] according to The Municipality of Baghdad. 


\section{CONCLUSION}

This article debates the literature review around the subjects of conservation in the urban context, urban conservation and socio-economic and sustainability aspects. It has asserted that conserving historic centres are significant in protecting cities identity, character and contributing in their economic development. The argumentation of this research concentrates on urban conservation and planning in Old Rusafa and indicates that the traditional urban fabric in Old Rusafa has witnessed an irreparable damage because of the weak definition of demands and an ambiguous formulation of what to preserve. It has also indicated that The Municipality of Baghdad is suffering from lack of clear vision and regulations in terms of urban conservation and this usually creates many obstacles when they want to prepare a plan for conserving traditional areas. As a result, the majority of urban conservation plans prepared by different groups for the city centre have been unsuccessful. Therefore, to create an effective urban conservation in Old Rusafa, we should enhance socio-economic environmental aspects and produce a comprehensive method to revitalizing urban components of the urban system in the city centre of Baghdad.

\section{ACKNOWLEDGEMENT}

I would like to express my thankful appreciation to Eamonn Canniffe for the support provided by him in the development of this research.

\section{REFERENCES}

[1] Everard, A.J. \& Pickard, R.D., Can Urban Conservation be Left to the Market? The Value of Partnership-Led Conservation Regeneration Strategies, pp. 619-632, WIT Press, Southampton, UK, 1997.

[2] Pendlebury, J., Conservation and regeneration: Complementary or conflicting processes? The case of Grainger Town, Newcastle upon Tyne. Planning Practice \& Research 17(2), pp. 145-158, 2002. DOI: 10.1080/14649350050135185.

[3] Akkar Ercan, M., Challenges and conflicts in achieving sustainable communities in historic neighbourhoods of Istanbul. Habitat International, 35(2), pp. 295-306, 2011. DOI: 10.1016/j.habitatint.2010.10.001.

[4] Assi, E., Limitations to community involvement in rehabilitation of historic areas. Advances in Architecture Series, 14, pp. 439-447, 2002. DOI: 10.2495/URS020421.

[5] Hiu Y, Hon C. Critical social sustainability factors in urban conservation: The case of the central police station compound in Hong Kong. Facilities. 2012;30(9/10):396-416. DOI: $10.1108 / 02632771211235224$.

[6] Yung, H. \& Chan, H., Critical social sustainability factors in urban conservation: The case of the central police station compound in Hong Kong. Facilities 30(9/10), pp. 396-416, 2012. DOI: 10.1108/02632771211235224.

[7] Al-Saffar M., Toward an Integrated Sustainable Urban Design Framework in the Historic Center of Baghdad. The International Journal of Environmental Sustainability. 13(1):31-52, 2016. DOI: 10.1109/EPE.2016.7521767.

[8] Ebrahimi, A.N., Effective urban values on conservation of historical contexts: The case of Isfahan - Iran. ArchNet-IJAR: International Journal of Architectural Research, 9(1), p. 181, 2015.

[9] Ardakani, M.K. \& Oloonabadi, S.S.A., Collective memory as an efficient agent in sustainable urban conservation. Procedia Engineering, 21, pp. 985-988, 2011. DOI: 10.1016/j.proeng.2011.11.2103. 
[10] Peerapun, W., Participatory planning in urban conservation and regeneration: A case study of Amphawa Community. Procedia - Social and Behavioral Sciences, 36, pp. 243-252, 2012. DOI: 10.1016/j.sbspro.2012.03.027.

[11] Glendinning, M., The Conservation Movement: A History of Architectural Preservation: Antiquity to Modernity 2013, Routledge, London, UK, 2013.

[12] Selim, G., Unfinished Places, ed. P. Ache, Routledge: New York, 2017.

[13] Cohen, N., Urban Conservation, MIT: Cambridge, MA; London, 1999.

[14] Albrecht, H., Urban Conservation Practices in Canada. Canada: The Standing Committee on Environment and Sustainable Development, Report of the Standing Committee on Environment and Sustainable Development, Canada. http://www.parl.gc.ca/ HousePublications/Publication.aspx $?$ DocId $=6054900 \&$ File $=5$ House of Commons Chamber DES Communes Canada, http://www.parl.gc.ca/content/hoc/Committee/411/ ENVI/Reports/RP6054900/envirp07/envirp07-e.pdf, 2013.

[15] Pendlebury, J. \& Strange, I., Urban conservation and the shaping of the English city. The Town Planning Review, 82(4), p. 361, 2011. DOI: 10.3828/tpr.2011.23.

[16] Su, X., Urban conservation in Lijiang, China: Power structure and funding systems. Cities, 27(3), pp. 164-171, 2010. DOI: 10.1016/j.cities.2009.12.004.

[17] Puren, K. \& Jordaan, T., Towards integrating built heritage resources in urban development through spatial planning. WIT Transactions on Ecology and the Environment, 191, pp. 209-220, 2014. DOI: 10.2495/SC140181.

[18] Koramaz, T. K. \& Gulersoy, N. Z., eds., Users' Responses to 2D and 3D Visualization Techniques in Urban Conservation Process 2011, IEEE, London, UK, 2011.

[19] Sarvarzadeh, S. K. \& Abidin, S.Z., Problematic issues of citizens' participation on urban heritage conservation in the historic cities of Iran. Procedia - Social and Behavioral Sciences, 50, pp. 214-225, 2012. DOI: 10.1016/j.sbspro.2012.08.029.

[20] Alsalloum, A., Heritage-Led Sustainable Urban Regeneration: The Development of an Assessment Model for World Heritage Sites Cities, University of Liverpool: Liverpool, 2011.

[21] Al-Akkam, A., Urban heritage in Baghdad: Toward a comprehensive sustainable framework. Journal of Sustainable Development, 6(2), pp. 39-55, 2013. DOI: 10.5539/jsd. v6n2p39.

[22] Pieri, C., Baghdad 1921-1958. Reflections on History as a 'Strategy of Vigilance', Mona Deeb. World Congress for Middle-Eastern Studies, Jun 2005, Amman, Jordan. Al-Nashra, 8 (1-2), pp.69-93, 2006. <halshs-00941214>

[23] Throsby, D., Investment in urban heritage conservation in developing countries: Concepts, methods and data. City, Culture and Society, 7(2):81-86, 2014. DOI: 10.1016/j.ccs.2015.11.002.

[24] Shwartz, A., Turbé, A., Julliard, R., Simon, L., \& Prévot, A.-C. Outstanding challenges for urban conservation research and action. Global Environmental Change, 28, pp. 39-49, 2014. DOI: 10.1016/j.gloenvcha.2014.06.002.

[25] Sinemillioglu, M. O., Akin, C.T. \& Karacay, N., Relationship between green areas and urban conservation in historical areas and its reflections: Case of Diyarbakir City, Turkey. European Planning Studies, 18(5), pp. 775-789, 2010. DOI: 10.1016/j. buildenv.2006.05.001.

[26] Auclair, E. \& Fairclough, G.J., Theory and Practice in Heritage and Sustainability: Between Past and Future 2015, Routledge, London, UK, 2015. 
[27] Bianca, S., Urban Form in the Arab World: Past and Present, Thames \& Hudson: London, 2000.

[28] Shin, H.B., Urban conservation and revalorisation of dilapidated historic quarters: The case of Nanluoguxiang in Beijing. Cities, 27(1), pp. S43-S54, 2010. DOI: 10.1016/j. cities.2010.03.006.

[29] JCP., Study on Conservation and Redevelopment of Historical Center of Baghdad City, Republic of Iraq: Amanat Al Assima, 1984.

[30] Wissen Hayek, U., Efthymiou, D., Farooq, B., von Wirth, T., Teich, M., Neuenschwander, N., et al., Quality of urban patterns: Spatially explicit evidence for multiple scales. Landscape and Urban Planning, 142, pp. 47-62, 2015. DOI: 10.1016/j.landurbplan.2015.05.010.

[31] Al-Hasani, M., Urban space transformation in old city of Baghdad - integration and management. Megaron Architecture, 7(3), p. 79, KARE Publishing, Istanbul, Turkey. ISSN:1309-6915, EISSN:1309-6915 2012. http://www.megaronjournal.com/jvi.aspx? pdir=megaron \&plng=eng\&un=MEGARON-14633. 